\title{
Negative Transfer of Chinese to College Students' English Writing
}

\author{
Zhiliang Liu \\ Foreign Language Department of Hui Zhou University, Yan Da Boulevard, Hui Zhou ,Guangdong 516007, China \\ Email: frank_168_888@163.com
}

\begin{abstract}
In China, in the process of college students' foreign language learning, English writing is the reflection of their integrating skills and it is also the process of rewriting based on gaining English knowledge. Meanwhile, Chinese college students' English writing is a cross-language and cross-cultural communicative behavior, and also a behavior of the transformation of thinking and cultural model. However, in the process of English writing, the negative transfer of Chinese influences students' writing. Here, according to the research to the students' writing and the relative questionnaire survey in Beihai College of Beihang University, this paper is a systematic and objective analysis on the negative transfer of Chinese to college students' English writing at the levels of lexis, sentence structure and discourse.
\end{abstract}

Index Terms - mother tongue transfer, negative transfer, Chinese, college students' English writing

\section{INTRODUCTION}

In the process of non-native language learning, there are many factors influencing the learners, such as the learners' internal and external factors. In this paper the focal point is the external factor, the transfer of learners' mother tongue.

Discussions of transfer begin with the work of American linguists in the 1940s and 1950s. Transfer is the influence resulting from the similarities and differences between the target language and any other language that has been previously (and perhaps imperfectly) acquired (Odlin, 1989). Yet while the work of Charles Fries, Robert Lado, and others was clearly a major catalyst for subsequent research, serious thinking about cross-linguistic influences dates back to a controversy in historical linguistics in the nineteenth century (Odlin, 1989). Odlin pointed out that negative transfer was quite possible and often probable in pronunciation, grammar, and so forth of second language learners. And Contrastive Analysis suggested that in the process of second language learning, the learners would meet the problem of mother tongue transfer. Therefore, for Chinese learners English is not their mother tongue and they will definitely meet the problem of negative transfer of Chinese.

Too few will gainsay the fact that writing is an art and that "he who has an art has everywhere a part," but too many will acknowledge that the art of writing is beyond their reach and that writing is their Achilles' heel in their academic or professional career(Xiao, 2007). According to this, we can see that writing is a key part in language learning. It is also true in foreign and second language learning.

\section{MOtHER TONGUE TRANSFER}

\section{A. Introduction}

Odlin considered that language transfer included the influence from mother tongue to second language acquisition and the borrowing from mother tongue to second language. Odlin called the former basic transfer, and called the latter borrowing transfer. Though the research on language transfer was cross-linguistic and inter-influence, most of the researches were about the influence from mother tongue to foreign language and second language acquisition. Therefore, language transfer became the name of mother tongue transfer (Yang \& Zhang, 2007).

\section{B. The Reason of Mother Tongue Transfer}

As Rod Ellis (1994) put it: The single paramount fact about language learning is that it concerns, not problem solving, but the formation and performance of habits. According to behaviorist theories, the main impediment to learning was interference from prior knowledge. Proactive inhibition occurred when old habits got in the way of attempts to learn new ones. In such cases, the old habits had to be 'unlearnt' so that they could be replaced by new ones. In the case of L2 learning, however, the notion of 'unlearning' made little sense, as learners clearly did not need to forget their L1 in order to acquire an L2, although, in some cases, the loss of the native language might take place eventually. For this reason, the behaviorist theories of L2 learning emphasized the idea of 'difficulty', defined as the amount of effort required to learn an L2 pattern. The degree of difficulty was believed to depend primarily on the extent to which the target language pattern was similar to or different from a native-language pattern. Where the two were identical, learning could take place easily through positive transfer of the native-language pattern, but where they were different, learning difficultly arose and errors resulting from negative transfer were likely to occur. 


\section{The Category of Mother Tongue Transfer}

1. Negative of mother tongue transfer

L2 learners are used to their mother tongue, when contacting a new language they will turn to the help of L1. The differences between L1 and L2, as well as the interferences of L1 will produce bad effect which is called negative transfer of mother tongue. Negative transfer refers to cross-linguistic influences resulting in errors, overproduction, underproduction, miscomprehension, and other effects. Those results will become stumbling stocks in the process of learning L2.

2. Positive of mother tongue transfer

But when the relevant item, structure or the language principle of two languages is similar, or even the same, the cross-linguistic influences result in correct language production. This process is called positive transfer of mother tongue. Unlike negative transfer, positive transfer can help the second language learners acquire more L2 knowledge and make less errors and mistakes in the process of learning L2.

\section{Brief Review of the Research of Mother Tongue Transfer}

The research of the transfer of mother tongue originated from America in 1940s and 1950s. Looking back the historical researches of language transfer of L2 in the late $20^{\text {th }}$ century, we can know that the researches focused on the influence of mother tongue in L2 acquisition. The research went through the contrastive analysis and Interlingua hypothesis. In 1957 Lado pointed out that in the process of second language learning, it was easily to learn the similarities of the L1 and L2, but difficult to learn the differences between them. In the following decades, the research about transfer of mother tongue made progress in every field and every level. On the whole, in foreign countries such researches focused on the manifestation and factors of it (Yang \& Zhang, 2007). In 1983, Selinker divided the transfer into positive transfer and negative transfer. In 1989, Odlin regarded that the facilitation of mother tongue depended on the amount of errors and the learning progress.

\section{Research of Negative Transfer of Chinese to College Students' ENGlish Writing}

\section{A. Quantitative Analysis}

1. Introduction

With the related theories, I started a research about the Negative Transfer of Chinese to College Students' English Writing in Beihai College of Beihang University. In this paper, randomly I have collected 40 non-English majors in the Department of Software Engineering and 30 English majors' writing papers in Grade Two, and 35 non-English majors' in the Department of Economic Management of Grade One. These writing papers are very typical and I have kept statistics of the errors occurring in the writings on the level of vocabulary and grammar. The data is as follows.

TABLE 1

\begin{tabular}{|l|l|l|l|}
\hline Students' level & $\begin{array}{l}\text { English majors } \\
\text { in Grade 2 } \\
\text { Manifestations of errors }\end{array}$ & $\begin{array}{l}\text { Non-English } \\
\text { majors in Grade 2 } 2 \\
\text { (40students) }\end{array}$ & $\begin{array}{l}\text { Non-English majors in } \\
\text { Grade 1 } \\
\text { (35students) }\end{array}$ \\
\hline Nouns & $18.2 \%$ & $8.4 \%$ & $8.9 \%$ \\
\hline Verbs & $34.4 \%$ & $40.2 \%$ & $46.3 \%$ \\
\hline Adjectives and Adverbs & $6 \%$ & $13.1 \%$ & $5 \%$ \\
\hline Prepositions & $5.3 \%$ & $8.5 \%$ & $8.2 \%$ \\
\hline Pronouns & $3 \%$ & $2.5 \%$ & $3.5 \%$ \\
\hline Articles & $3 \%$ & $1.3 \%$ & $3.2 \%$ \\
\hline Match cases and Punctuations & $0.5 \%$ & $3.8 \%$ & $4.5 \%$ \\
\hline Spellings & $25.2 \%$ & $16.2 \%$ & $17.4 \%$ \\
\hline Others & $4.4 \%$ & $6 \%$ & $3 \%$ \\
\hline
\end{tabular}

\section{Description of the data}

According to table 1, it's not difficult to find that the incorrect use of verbs accounts for the most proportion of the whole errors and mistakes, no matter in Grade One or Two, or no matter to English or non-English majors. Besides, the numbers are different between English and non-English majors, and between Grade One and Two of non-English majors.

\section{B. Qualitative Analysis}

\section{Introduction}

Chinese and English are of two languages belonging to different language systems, so college English students make a lot of errors and mistakes in their papers. Many linguists agree that in Chinese the notion and the meaning of words and sentences are important, the form is minor. Chinese people can accept the sentence without a full structure. While in English the word form and sentence structure are important. The negative transfer of Chinese influences the college 
students' English writing in many aspects. Based on the above relative theories, some analysis will be represented in this chapter.

2. Lexical errors

Chinese and English almost share the same classification of the words. There are noun, verb, adjective, adverb, pronoun, preposition and article in the classification. However, there are many different language rules and principles in word forming and using.

(1) Spelling errors

The spellings are extremely different. In spelling, Chinese words are formed by strokes, such as 我, 中, 大, 汉 and so on, while the English ones are formed by letters, just like the English words used here in this paper. The different order of the 26 English letters can form numerous words. So for the English learners, it is not easy to remember all the English words and write them correctly. Moreover, some words are very similar in form, such as "there and their, cup and cap, cut and cat, compliment and complement" and so on. Therefore, the learners will be easy to mix some words and can't remember the words accurately. In table 1, the proportion of the wrong spelling takes up a large number ranking in the second place. By comparing the English majors and the non-English majors, it is not that hard to get the English majors make more such mistakes than the non-English majors. It is because the English majors use more complex English words than the non-English majors, the latter usually use the simplest words to avoid spelling mistakes to get higher scores, but for the former, if they want to get higher scores they should not just use the simple words but also the new and complex ones. However, from the research I find that most spelling mistakes don't lead to readers' misunderstanding of the words or even the sentences. Those wrong spellings are mostly of missing or adding some English letters, so the readers will know or guess the meaning from the wrong words or the context, such as the words written by the students "techological, desiger, accroding, somthing, ralatively, blackbood, afaid, omportant".

(2) Vocabulary errors

Besides different word spelling, different vocabulary also causes Chinese negative transfer to English writing. Zhonghua Yang (2009) pointed it out that the negative transfer of vocabulary reflected on the collocation and choice of words, derivative words, articles and the use of singular-plural form of words and so on. He thought that most errors were the incorrect use of choice and collocation of words. When writing, students would translate the main idea from Chinese subconsciously, so Chinese semantic transfer led to a large number of Chinese-English sentences.

In Xiaohui Li and Wen Chen's research (2006), they found that in lexical errors the wrong collocation took a proportion of $17.9 \%$, the misuse of gender of words is $12.5 \%$; the indiscriminate use of the words takes up $8.9 \%$. They thought English and Chinese belonged to two different language systems and their cultural and social backgrounds were also different. In my research, I found the wrong collocation of words mostly involved the collocation with preposition. In most cases, the students used wrong prepositions or didn't use any preposition at all. In table $1,5.3 \%$ errors and mistakes of prepositions are made by the English majors and about $8 \%$ by the non-English majors. The numbers are very near between the English and non-English majors. It shows that such errors and mistakes are common in college English writing. Because Chinese people use prepositions less than the English and there are not so many strict rules in using prepositions in Chinese. In English sentences most prepositions are fixed to certain phrases and contexts. For example, in the following Chinese sentences “我在中国旅游”,“我在去教室的路上”, and “我在早上九点的时候学习 了英语”, the preposition in every sentence is“在”. But if a learner translates every sentence into corresponding English sentence, the translations should be "I am travelling in China", "I am on my way to the classroom" and "I studied English at 9:00am". So the Chinese character “在”is translated into in, on and at in different English sentences. So for the English learners in China, the different uses of prepositions between the two languages will affect their English learning and acquisition. Look at those samples in the students' writing.

(1) The effect of exercise of our health are obvious.

(2) Exercise take many advantages on our health.

(3) So we always do some exercises are good at our health ....

(4) Now, let me show you one my memories for you.

(5) In the party, everyone are be good sing song.

Here in the following explanation, other errors and mistakes will be ignored except the collocation misused. From the above samples, the preposition of in the phrase of our health in sample (1), on in sample (2), and at in sample (3) are misused. While in sample (4) and (5) the prepositions are ignored. That's because the Chinese students can't find the exact English preposition in writing. The students get used to put their known knowledge to a second language learning, they do not get a very clear idea to use prepositions in English phrases or sentences. The right prepositions in sample (1)-(3) in order should be on, to and for/to, while in sample (4) of should be added in front of the word my and in sample (5) at should be added at the back of good. In English, the noun effect should be followed by the preposition on to describe one thing or person. With the same reason, it is also true to many English words. And the Chinese meaning of every correct sample will be as the following:

(1) 运动对我们健康的效果很明显。

(2) 运动带给我们健康很多好处。 
(3) 所以我们总是做一些对我们健康有好处的运动。

(4) 现在, 让我为你展现我的一个回忆。

(5) 在晚会上, 每个人都善于唱歌。

With the above explanation, it is not that difficult to understand the English and Chinese sentences of every sample except sample (4). From the meanings of sample(1)-(3), the students realize that there should be preposition in each English sentence, so they choose one, but they are affected by Chinese in which there is no exact one to match the notional words. Appearing in the English sentences, the prepositions are the replacements. While in the Chinese sentence of sample (4) there is no preposition in the second clause, the phrase one of my memories is understood and translated as “我的一个回忆”. The words in two different languages are used differently with different language rules. Viewed from the above analysis, not only the example of preposition is used very differently, but also the part of many other words, such as nouns, verbs, adjectives, adverbs, and articles.

3. Sentence structural errors

Jiwan Bi (1994) said that in foreign language teaching, in Chinese-English translation and in cross-cultural communication the differences of Chinese and English sentence structures often became a big obstacle. Jingni Quan (2007) pointed out that someone once did a research on English learners in China about the interference from Chinese to foreign language learning. The result showed that the same sentence style of Chinese and English could enhance the understanding of the English sentence, while the different sentence styles of them would influence the learners with lower English level to the speed of understanding. Only after the learners had mastered the English sentences skillfully, could their speed of understanding be improved (Quan, 2007).

Ruifang Fang (2007) pointed it out that English was a morphological language in which the sentence was subject-predicate-oriented. Subject and predicate were in restraint of grammatical agreement. She also thought that the English sentences are enclosed. It was the same as what Wang Li had said that the western grammar was hard, not flexible, while the Chinese grammar was just the opposite, it was soft and flexible. So in English writing, students should master the English grammar skillfully, or they will make different kinds of errors and mistakes.

In the research of this paper, there are more than $90 \%$ non-English majors using simple sentence in English writing. In China, people use simple sentence much more often than complex sentence. Just take the simple pattern " $\mathrm{S}+\mathrm{V}+\mathrm{O}$ " as an example, Chinese people use this pattern very often in daily life, such as: 小黄正在写作业。你们去游览了长城。 他们不愿意去找工作。The learners get familiar and master this pattern skillfully, so they use it in English writing, and the sentences with such pattern are usually correct. These sentences are samples: "You did a lot of exercises. The exercise is good for our health. At the same time, the government should establish some relevant decrees. It will let us keep thin." and so on. However, not all patterns between two different languages are similar, so what will happen if there are different sentence patterns?

In English, clauses and complex sentences are used widely, while in Chinese they are rarely used except the adverbial clause. Most of the learners who learn English at the very beginning haven't heard of the subject clause, object clause, predicative clause, or attributive clause. To those learners, such clause patterns are new to them, and if they want to use them in writing they should learn to master them. Because of those reasons, many errors occur in English writings. With the continuously learning English, the errors are not overcome completely, though some are overcome, especially for the non-English majors in college. As I mentioned before, more than $90 \%$ non-English majors used the simple sentences, not the complex ones in English writing. Besides the above reason, there is another reason that they don't master the complex sentence patterns, let alone using them skillfully. Here are the non-English majors' samples which are incorrect:

(1)...eat something who have iron element.

(2) On one hand, doing more exercise can strengthen our body, that help us resistant the virus, let us less suffer the disease.

(3) There are many ways can take.

(4) When you at a place was very cool..."

The correct ones should be:

(1)...eat something that has iron element.

(2) On one hand, doing more exercise can strengthen our body, which helps us resistant the viruses, letting us suffer less diseases.

(3) There are many ways which we can take.

(4) When you were at a place which was very cool..."

These sentences or clauses involve antecedent misuse. So even the students want to use the complex sentences in writing to get higher scores, they don't use them correctly. This phenomenon is not just happening to the non-English majors, but also to English majors. In the research, every English major uses simple and complex sentences, but there are still similar errors in using complex sentences. Some wrong sentences appear in the writings:

(1)...of the product what they want to buy.

(2) For example, the fact didn't as same as which say in the adverts. 
(3)...so that we can make a choice that we need to buy it or not.",

But the correct ones should be:

(1)... of the product which they want to buy.

(2) For example, the fact wasn't as same as what was said in the advertisements.

(3)...so that we can make a choice whether we need to buy it or not."

From the samples, the influences of different sentence patterns exist universally in English writing for Chinese college students.

4. Discourse errors

Judged from the grammar level, the lexical and sentence structural errors just occur in a single sentence. However, in a whole writing work the discourse should not be ignored. Shuhua Tong (2008, p.52) wrote: Robert B Kaplan thought that the organization and development in an English discourse were linear. That was, an English paragraph usually began with a point which was directly pointed out and then developed by the following sentences in that paragraph. In the process of pointing out the point, each sentence in the paragraph was naturally produced after the previous one. Therefore, the meaning of the paragraph was developed in a linear order, and then was filled in by details step by step. Finally, the topic was full gradually. On the contrary, the development of Chinese discourse was spiral. The topic of the discourse wasn't presented with a direct way but an indirect one. Anyway, the different thinking models between Chinese and English influence the organization of discourse in writing. Especially, the Chinese spiral thinking model will affect the English writing directly in discourse. Based on this theory, a group of numbers of the research is as follows.

TABLE 2

\begin{tabular}{|l|l|l|}
\hline \multicolumn{1}{|c|}{ Students' level } & $\begin{array}{l}\text { English majors } \\
\text { in Grade 2 } \\
\text { (30students) }\end{array}$ & $\begin{array}{l}\text { Non-English } \\
\text { Majors in Grade 2 } \\
\text { 40students) }\end{array}$ \\
\hline 5 points & $3.33 \%$ & 0 \\
\hline 6 points & 0 & $7.5 \%$ \\
\hline 7 points & $30 \%$ & $35 \%$ \\
\hline 8 points & $20 \%$ & $35 \%$ \\
\hline 9 points & $10 \%$ & $22.5 \%$ \\
\hline 10 points & $10 \%$ & 0 \\
\hline 11 points & $6.67 \%$ & 0 \\
\hline 12 points & $16.67 \%$ & 0 \\
\hline 13 points & $3.33 \%$ & 0 \\
\hline
\end{tabular}

In the research, to English majors in Grade 2 the writing topic is The Effects of Advertising, while to the non-English majors the topic is The Effects of Exercise on Our Health. And the full mark of the English writing is 15 points, and only with 9 points can the students pass the writing assignment. Besides the words and sentence structure, the organization of the discourse will affect the scores, but only the discourse is discussed here. From table 2, the scores range from 6 to 12. And the fact that only 22.5\% non-English majors and 46.7\% English majors get the passing grade is showed in table 2. It means that more English majors pass the assignment than the non-English majors. Though the topic is not the same, the proportion of those two groups of students is reasonable. The English majors learn English grammar in college and they pay more attention to English, so they can avoid more Chinese negative transfer in English writing. However, the students majoring in other courses don't care too much about English. Thus under the influence of the Chinese thinking model, most discourse errors in the research are about lacking coherence between sentences or between paragraphs, not emphasizing the main idea, and contradiction of the opinion and so on. Here is one of the articles form the students.

The Effects of Exercise on Our Health

Most of people like to do some exercises, the boys are better like than the girls. They are interested in exercising.

The exercise is good for our health. It can let us have a rest. After that, people can work and study good. And then, the exercise can make people stronger. So, people are not easier have a ill.

But the exercise has something bad for people. When people do some exercises, people are easy to have a harm.

In my opinion, people do some exercises, they should not do the exercises so hard. People also often want to do some exercises.

The above article is full of errors and mistakes. From the angle of discourse errors, first, the article is lack of coherence. It's because in English every sentence and every paragraph should be linked by some words or phrases, while in Chinese there are no such strict rules. Second, the structure of the whole discourse is confusing. The writer neither used the pure Chinese spiral thinking model nor the English linear thinking model, but mixed the two different thinking models. He pointed out one opinion, then turned to the other irrelative details or skipped to another opinion. So 
finally, the reader didn't know whether the writer was in favor of exercise or not.

To sum up, if the English learners are not aware of the Chinese negative influence, they will make a lot of errors and mistakes in the whole discourse.

\section{Students' Attitude to the Negative Transfer of Chinese to College Students' EnGLish Writing}

\section{A. Introduction}

Due to the fact that there are so many errors and mistakes appearing in college students' writing just because of the negative transfer of Chinese, I made a questionnaire survey about students' attitude to the influence of Chinese to college English writing in Beihai College of Beihang University. I handed out some questionnaires to the students whose writing works I used to analyze the negative transfer of Chinese. And I picked out 43 pieces of the feedback of the questionnaires randomly to explain certain phenomenon; the questionnaires are all from the students whose writing articles I used to do the research in chapter 3.

\section{B. Result of the Survey}

In the feedback of the questionnaire, $67.43 \%$ students thought that Chinese was helpful to college English writing, and just $11.63 \%$ thought that Chinese would influence English writing, but $2.32 \%$ thought that Chinese not only helped but also influenced the English writing. There were still $18.6 \%$ students who were not clear about whether Chinese would help English or not. But after I showed them that Chinese did influence their English writing in many aspects, $37.21 \%$ students recalled that they had tried to avoid the errors and mistakes resulted from Chinese in their writing, but $62.79 \%$ didn't realize the mistakes. Though none of them got the effective method to deal with such errors and mistakes, everyone wanted to make fewer of them and wrote a perfect article.

\section{Description of the Result}

Compared the errors and mistakes in students' writing with their attitude to the negative transfer of Chinese to college students' writing, it is confusing for people to see that most college students thought that Chinese was helpful to their English writing. But if it is analyzed as follows, this problem will be understood.

Nowadays, most Chinese college students are adults and they have learnt English for more than 6 years from junior middle school years. Some even learnt it from babyhood or childhood. They have learnt some basic and useful English words, sentences, discourses, and grammars and so on. However, they have mastered Chinese grammar far better than that of English because they can't avoid using it in daily life and study. They put Chinese in English learning and acquiring subconsciously. When they encounter difficulties in English learning and acquisition, they will turn to the help of their mother tongue subconsciously, so they think that their use of Chinese is helpful in English writing, ignoring the influence of it. But the fact is that Chinese influences their writing without being realized.

\section{INSPIRATIONS FROM THE RESEARCH AND STRATEGIES}

\section{A. Inspirations from the Research}

Since Chinese influences college students' English writing without students' realization, it is necessary to adapt some useful strategies to arouse students' attention to the influence of Chinese to English writing and improve their writing skills. Though not all the errors and mistakes in college English writing results from the negative transfer of Chinese, to some extent, Chinese does result in some errors and mistakes. Tao Feng (2005, p.33) said, "The negative transfer of Chinese was temporary, and it could be overcome by practice. If the transfer and the condition of its effect were noticed, to some extent, the negative transfer would be reduced or even be avoided. The negative transfer would be reduced if some strategies were adapted in teaching." In language learning, writing is an output and an end of a learning period. He thought that both teachers and students should take some strategies.

As writing is an output, the input is very important, such as reading, listening. Writing is a comprehensive task to language learners. It doesn't work if the learners have only mastered the writing methods and shortcuts.

\section{B. Strategies to the Teachers}

Teachers play an introductory role in college English writing. Though the teachers know how to deal with some errors and mistakes resulting from Chinese, they can't force the students not to make such things, or help them to correct the errors and mistakes in a short time. Learning is a process, let alone the L2 learning. The students need time to improve their ability in using foreign languages.

First, teachers should tolerate students' errors and mistakes, and point out the errors and mistakes with an acceptable device. Though some people hold an idea that teachers should point out students' shortcomings and help them to correct the shortcomings, nowadays the students have a strong sense of self-esteem. Most students don't like to be told they are wrong in public. Therefore, teachers should know the students' psychological idea whether they can accept the shortcomings or not in public. Moreover, the shortcomings resulting from the negative transfer of Chinese will be overcome gradually. But the important thing is that teachers should remind the students that there is such transfer. Students need transitive period to overcome such shortcomings. Therefore, teachers should allow students to make such 
shortcomings, and then courage them to correct the shortcomings.

Second, to help students to overcome the shortcomings, teachers should guide the students to reinforce the input to English writing. As it is pointed out at the second paragraph of this section, reading, listening are of the input. Teachers should make an environment for students to practice those aspects. For example, teachers can assign a task that every student should read one or two English articles, and then randomly ask one of them to retell the story and at the same time to present personal opinions. Or the teachers can turn on a computer, letting the students listen to English words, phrases, clauses, sentences or dialogues carefully, and then ask them to make up a full story or full context. No matter what form the practice or activity is, the more English full sentences and contexts the students contact, the closer they will get to their better writing. As the time passing by and with the progress of their input, the output will be stronger and stronger.

Finally, teachers also should teach students the differences between Chinese and English. In the comparing and contrasting the similarities and differences of the languages and the relevant culture, the students' knowledge can be broadened, and then they can improve their writing maximally.

\section{Strategies to the Students}

However, the most important factor in the process of English writing is the student. They are the main role. Chunliang Zhang (2009) said that R. Ellis regarded the transfer of mother tongue as an L2 learner's learning strategy because of the learner's lacking of the L2 knowledge. And Stern regarded the transfer and the influence of mother tongue as a foundation for foreign language learning. He also pointed it out that learners took the mother tongue as a reference object in foreign language learning. Zhang considered the use of mother tongue as learner's creative behavior, which was an important part in the Interlingua system that the learner created by themselves before they mastered the target language. Therefore, the students' attitudes and strategies are very vital in the whole process of English writing.

First of all, students should put their interest and enthusiasm to English learning. To some extent, interest and enthusiasm will give students power to overcome the shortcomings in the writing process.

Second, students should face their errors and mistakes positively. They should know that the negative transfer of Chinese can be overcome gradually in mind. Therefore, they will be confident to their English writing.

Third, students should follow their teacher and improve their abilities of reading, listening, speaking purposefully. Rome is not built in a day. Only if they continuously practice reinforcing the inputs, input will help the students with their writing. And the negative transfer of Chinese will be naturally weakened.

\section{CONCLUSION}

\section{A. Summary of the Study}

Viewed from the theories, in the process of English learning, it is inevitable for Chinese college students to make errors and mistakes in English writing. But under the teachers' guiding and the students' purposeful and careful learning, some difficulties resulting from the negative transfer of Chinese will be overcome gradually.

This paper mainly aims at analyzing the errors and mistakes caused by the Chinese influence on college students' English writing. The errors in the samples were divided into three categories, namely, lexical errors, sentence structural errors and discourse errors. The questionnaire aims at analyzing the students' attitudes to the negative transfer of Chinese to their English writing. Based on the theories and the data of the research, it is safe to say that Chinese does influence college students' English writing in China.

\section{B. Limitations of this Study}

The limitations of this study are as follows.

The students' writing tasks in this research are different, though the topic is almost the same, the content is very different. The number of the students' in the questionnaire is not so large, which may influence the result of the research.

The categories of the errors and mistakes are not so detailed, and the interpretation of some errors is not that complete. It is difficult to explain all the errors and mistakes appearing in the students' writing, only some examples are picked out to interpret the negative transfer of Chinese to college English writing.

\section{Suggestions for Further Research}

Because society is developing and human being is progressing, the old researches should be developed again by the new generation to coincide with the reality. In the fast growing global world, the language and the culture are changing in a fast pace. Some differences of the two different languages will be identified and mastered by the language learners. And the factors in negative transfer of Chinese will be changed with the development of the learners' knowledge, so the detailed, all-around and new researches about the negative transfer of Chinese are needed very much. Therefore more researches with larger samples should be done in the coming days.

\section{REFERENCES}

[1] Chunliang Zhang. (2007). Negative transfer of mother tongue and teaching inspiration in college English writing. Northeast 
University Journal (Social Science Edition) 68.6, 22-26.

[2] Cuixia Li. (2008). Negative transfer phenomenon and responding strategy of mother tongue in second language acquisition. Research of Sustainable Education 8.2, 38-40.

[3] Eli Hinkel. (1999). Culture in second language teaching and learning. Shanghai: Shanghai Foreign Language Education Press.

[4] Fushou Xiao. (2007). Principles and strategies on the teaching of English writing. Shanghai: Shanghai University Press.

[5] Jingni Quan. (2007). Function of mother tongue in foreign language teaching. Information of Science and technology: Academic Edition 15.29, 40-43.

[6] Halliday, M.A.K. (2007). Language and education. Beijing: Beijing University Press.

[7] Lianrui Yang \& Delu Zhang. (2007). Research of second language acquisition and foreign language teaching in China. Shanghai: Shanghai Foreign Education Press.

[8] Michael O'Malley Anna Uhl Chamot, J. (1990). Learning strategies in second language acquisition. Shanghai: Shanghai Foreign Language Education Press.

[9] Ringbom, H. (1987). The role of the first language in foreign language learning. Clevedon, Avon: Multilingual Matters.

[10] Ruifang Liu. (2007). Negative transfer of Chinese thinking in English sentence writing. Journal of Chi Zhou College 12. 6 , 22-25

[11] Rod Ellis. (1999). The study of second language acquisition. Shanghai: Shanghai Foreign Language Education Press.

[12] Shuhua Tong. (2008). The effect of differences between Chinese and English thinking on the discourse writing organization of second language. Yunmeng Academic Journal 8.3, 51-53.

[13] Stern, H.H. (1983). Fundamental concepts of language teaching. Shanghai: Shanghai Foreign Language Education Press.

[14] Tao Feng. (2005). The effect and responding strategy of Chinese negative transfer on English writing. Basic English Education $16.4,32-35$.

[15] Terence Odlin. (2001). Language transfer cross-linguistic influence in language learning. Shanghai: Shanghai Foreign Language Education Press.

[16] Wenzhong Hu. (1994). Culture and communication. Beijing: Foreign Language Teaching and Research Press.

[17] Xiaohui Li \& Wen Chen. (2007). Chinese negative transfer on English writing. Higher Education Research on Science and Engineering 10.2, 19-23.

[18] Zhonghua Yang. (2009). The effect of mother tongue transfer on English writing. Teaching and Management 11.3, 16-20.

Zhiliang Liu was born in Wuqi, Shaanxi Province, China in 1964. He received his M.Ed. degree in applied linguistics from Northwest Normal University, China.

He is currently a professor in the Foreign Language Department of Hui Zhou University, China. His research interests include second language acquisition and applied linguistics. 